\title{
A functional genomics approach to viral-host interactions for HIV
}

\author{
Stephen J Elledge \\ From Immunodiagnosis of Tuberculosis: New Questions, New Tools \\ Virginia, VA, USA. 21-23 September 2008
}

New screening methodologies developed over the past five years, based on a revolution in understanding the biology of double-stranded DNA and RNA interference, provide the tools for genetic screening of mammalian cells. HIV is a straightforward RNA virus, and the challenge our team has tackled is to identify the host proteins the virus needs to replicate using short strands of small interfering RNA (siRNA) to block their function. The siRNA screen is an arrayed format-siRNAs to one gene per well-using liquid-handling robots. Cells are transiently transfected with siRNAs, producing protein knock-down in a gene-specific manner that is effective for about a week. Using a SMARTpool library produced by Dharmacon with four siRNAs per pool and 21,121 genes, we completed a validation round with the four individual siRNAs.

Seventy-two hours after transecting the cells with siRNA, infected cells and supernatant were harvested, and the viral load measured. The cellular analysis indicated how well the virus had infected the cell and expressed a key capsid protein p24 protein; the supernatant indicated how efficiently the virus budded out of the cell in a functional form. We discovered several proteins that appear to be genetically important to the HIV lifecycle. Using bioinformatics, we were able to map out the role the host factors played in the viral life cycle, from the virus getting into the cell, to its integration into the DNA of the cell's nucleus, to the messenger RNA (mRNA) processing of the virus; and to its export into the cytoplasm and out of the cell. Genetic screening results provided a rediscovery of all known host dependency factors in the HIV lifecycle states and confirmation of Host Dependency Factors (Rab6, Vps53, TNPO3, Med28), suggesting the model is effective.

Correspondence: selledge@genetics.med.harvard.edu

Harvard Medical School, Harvard University, Boston, Massachusetts, USA
One of the proteins identified in the screen (TPNO3), a karyopherin, is likely to be the host factor that permits HIV access to our nucleus for integration into our genome. Our research demonstrates that when TPNO3 was knocked out by any one of eight siRNAs, the virus was prevented from infecting the cell and integrating into the genome. Utilizing unbiased whole genome screens which can be used for any pathogen, to identify host proteins that actively support replication - could provide new drug targets. The way the screen is designed can profoundly influence which genes are uncovered and different screening platforms will yield different results, making the technique potentially very flexible.

Published: 17 December 2010

doi:10.1186/1753-6561-4-S3-O6

Cite this article as: Elledge: A functional genomics approach to viral-host interactions for HIV. BMC Proceedings 2010 4(Suppl 3):O6.

Submit your next manuscript to BioMed Central and take full advantage of:

- Convenient online submission

- Thorough peer review

- No space constraints or color figure charges

- Immediate publication on acceptance

- Inclusion in PubMed, CAS, Scopus and Google Scholar

- Research which is freely available for redistribution 